\title{
CryptoNight Mining Algorithm with YAC Consensus for Social Media Marketing Using Blockchain
}

\section{Anwer Mustafa Hil ${ }^{1}$, Fahd N. Al-Wesabi ${ }^{2}$, Hadeel Alsolai ${ }^{3}$, Ola Abdelgney Omer Ali ${ }^{4}$, Nadhem Nemri ${ }^{5}$, Manar Ahmed Hamza ${ }^{1, *}$, Abu Sarwar Zamani ${ }^{1}$ and Mohammed Rizwanullah ${ }^{1}$}

\author{
${ }^{1}$ Department of Computer and Self Development, Preparatory Year Deanship, Prince Sattam bin Abdulaziz University, \\ Alkharj, Saudi Arabia \\ ${ }^{2}$ Department of Computer Science, College of Science \& Art at Mahayil, King Khalid University, Saudi Arabia \& Faculty \\ of Computer and IT, Sana'a University, Yemen \\ ${ }^{3}$ Department of Information Systems, College of Computer and Information Sciences, Princess Nourah bint Abdulrahman \\ University, Saudi Arabia \\ ${ }^{4}$ Department of Information Technology, College of Computer, Qassim University, Buraydah, Saudi Arabia \\ ${ }^{5}$ Department of Information Systems, College of Science \& Art at Mahayil, King Khalid University, Saudi Arabia \\ *Corresponding Author: Manar Ahmed Hamza. Email: ma.hamza@psau.edu.sa \\ Received: 03 August 2021; Accepted: 10 September 2021
}

\begin{abstract}
Social media is a platform in which user can create, share and exchange the knowledge/information. Social media marketing is to identify the different consumer's demands and engages them to create marketing resources. The popular social media platforms are Microsoft, Snapchat, Amazon, Flipkart, Google, eBay, Instagram, Facebook, Pin interest, and Twitter. The main aim of social media marketing deals with various business partners and build good relationship with millions of customers by satisfying their needs. Disruptive technology is replacing old approaches in the social media marketing to new technology-based marketing. However, this disruptive technology creates some issues like fake news, insecure, inconsistency, inaccuracy and so on. These issues contribute economic instability in the society, diminishing the level of trustworthy. To overcome these issues, this paper we present blockchain as disruptive technology for social media marketing. Blockchain plays a vital role on social media marketing by providing secure to the company page in the website. The properties of disruptive potential of blockchain on social media marketing is transparency, security, reliability and immutability. This paper presents a new framework for disruptive technology in blockchain social media marketing using fusion of CryptoNight mining algorithm with YAC consensus algorithm [BCDSMM-CNYAC]. This mining algorithm provides high CPU efficiency, high dimensionality of secure and detecting falsifying data attack in the social media marketing. For the data analysis we proposed ANOVA analysis method regarding to the factors of age, time, frequency visiting times of social media platform. For reliability analysis of data Cronbach's alpha tests are implemented.
\end{abstract}

Keywords: Cryptonight; disruptive technology; smart contracts; social media; security; YAC 


\section{Introduction}

Social media platforms will become a part of our day-to-day life. It is an Internet-based platform in which people canshare and gain knowledge via mobile based application or network-based application [1-3]. The most popular social media platforms are Twitter, Instagram, Facebook, LinkedIn. It is reported that $90 \%$ of people are having social media account. It is one of the best platforms to connect people, promote their product and establish relationship between consumers and stakeholders [4].

Social media marketing creates an interaction between retailer and consumers through social media platform. The main issues are insecure in transaction, maintaining the privacy of consumer details as well as stakeholders, accessing the relevant information about some product, difficult to identify the fake information, malicious activities etc. To overcome these issues in the traditional social media marketing we implement blockchain as disruptive technology. This blockchain as disruptive technology in the social media platforms concerns about the consumers, filtering the fake news.

Blockchain technology is a decentralized-based and it is improving the security in the transaction of data, connecting millions of active consumers, establishing the online business in a prominent way $[5,6]$. Blockchain as a disruptive will revolutionize the social media marketing in an authenticated way [7]. In addition to that, it distributes the data with high power of control to the consumers, so data will be reliable. It addressed the fake data [8].

This paper presents a new framework for disruptive technology in blockchain social media marketing using fusion of CryptoNight mining algorithm with YAC consensus algorithm [BCDSMMCNYAC]. In BCDSMM-CNYACalgorithm it uses Proof of Work (PoW) and offers high efficiency in the CPU usage. The main aim of this algorithm is generating the hash value in a fast with private key. It increases the transaction load, that is good scalability and undergoes cryptographic test by implementing YAC consensus algorithm. Therefore, it produces high dimensionality of secure. Social media marketing has become an effective and efficient way of relationship between the consumers and marketers. The main contribution of this work is:

- Blockchain as disruptive technology in the social media marketing assists the consumers taking the decision of buying product in a secure way.

- 2.To analysis the consumer's expectation and availability of sources in the social media platform.

- To promoting their business in the online platform in an efficient way by filtering the fraud information by using CryptoNight and YAC consensus algorithm.

The paper has been organized as follows: Section 2 describes about the review of the literature, Section 3 introduces framework for blockchain as disruptive technology in social media marketing, Section 4 discusses about the experimented results and Section 5 concludes the paper with future directions.

\section{Literature Review}

In the last decade, growth of technology and usage of social media platform has increases dramatically. It reaches millions of people to change their life style as partners, marketing managers, marketing producers and stakeholders [9]. The social media users communicate with one another and influencing their brand of product in the online market which will be a good implications of social media marketing field. Disruptive technology concept was introduced in 1990, and modified version of disruptive innovation which includes conceptualization of data [10]. 
Social media marketing promotes the user's interaction between consumers and marketers via Facebook, Twitter, LinkedIn etc [11]. This paper [12] proposed an effective power on usage of social media by youngsters focusing only Instagram for their marketing purpose. Similarly, Twitter also considers as an effective tool for relationship between marketer and consumer [13]. The major issues in the existing system are fail to keep all sensitive transaction information in social media marketing as privacy. Spreading fake information about the product to attract the consumers [14].

To overcome these issues our proposed work implements the blockchain as disruptive technology, itreduces the risk in transaction of data, reducing the cost, increasing the usage time, accessing the information in quicker way, providing privacy and avoiding fake information [15]. The brief study on social media analysis using block chain technology is discussed in articles [16,17]. The blockchain act as best security technique for social media data analytics.

Data stored in distributed ledger of blockchain technology which keeps the data transparency and reliability. The smart contracts in blockchain automatically run the code when it meets consumer's requirements. Tab. 1 shows the summary of the related works.

Table 1: Summary of related work

\begin{tabular}{|c|c|c|}
\hline Author name & Technology & Description \\
\hline Ghose et al. [18] & Blockchain & $\begin{array}{l}\text { Collection of transaction is carried } \\
\text { out in ledger and it is considered as } \\
\text { virtual book. }\end{array}$ \\
\hline Ma et al. [19] & Blockchain & $\begin{array}{l}\text { Impact of dynamic marketing } \\
\text { management in the social media. }\end{array}$ \\
\hline \multirow[t]{2}{*}{ Ghose et al. [20] } & Cryptocurrency & $\begin{array}{l}\text { Accessing the transaction in the } \\
\text { authenticated way. }\end{array}$ \\
\hline & Machine learning & $\begin{array}{l}\text { Social influence identification by } \\
\text { using machine learning and } \\
\text { simulation method in the social media. }\end{array}$ \\
\hline Pekgün et al. [21] & $\begin{array}{l}\text { Statistics method in behavioural } \\
\text { of users }\end{array}$ & $\begin{array}{l}\text { Promote the advertising and } \\
\text { marketing of the product in the social } \\
\text { media. }\end{array}$ \\
\hline Lee et al. [22] & Big data & $\begin{array}{l}\text { Twitter social media platform big data } \\
\text { analytic is used understanding } \\
\text { customer behaviour. }\end{array}$ \\
\hline Hou et al. [23] & Blockchain-cloud based & $\begin{array}{l}\text { Supporting of online marketing in } \\
\text { scarce of indisputable. }\end{array}$ \\
\hline Singh et al. [24] & Game theory & $\begin{array}{l}\text { Assessment of consumer's behaviour } \\
\text { based upon their opinions which are } \\
\text { posted in the social media. }\end{array}$ \\
\hline Gunnec et al. [25] & Machine learning & $\begin{array}{l}\text { Processing of unstructured data in the } \\
\text { Amazon product and tagging the } \\
\text { review of customer. }\end{array}$ \\
\hline $\begin{array}{l}\text { Ramanathan et al. } \\
\text { [26] }\end{array}$ & Game theory & $\begin{array}{l}\text { Exploring the different scenarios of } \\
\text { data in social media platform. }\end{array}$ \\
\hline
\end{tabular}

(Continued) 
Table 1: Continued

\begin{tabular}{lll}
\hline Author name & Technology & Description \\
\hline Lobel et al. [27] & Support vector machine & $\begin{array}{l}\text { Social media data Analysis quality of } \\
\text { the product in the food supply chain } \\
\text { management. } \\
\text { Designing the product and } \\
\text { Hair et al. [28] }\end{array}$ \\
& Genetic algorithm & \begin{tabular}{l} 
incorporates in the social network. \\
\hline
\end{tabular}
\end{tabular}

\section{Framework for Blockchain as Disruptive Technology in Social Media Marketing Using CryptoNight (BCDSMM-CNYAC)}

Blockchain as a disruptive technology used in public and private social media marketing management. By this proposed method BCDSMM-CNYAC collect the inputs from various social media platform like Amazon, Facebook, Twitter, Instagram, LinkedIn, Snapchat etc. The proposed work is shown in the Fig. 1. This proposed work consists of four layers.

- Application Layer

- Meta-Application Layer

- Network Layer

- Storage Layer

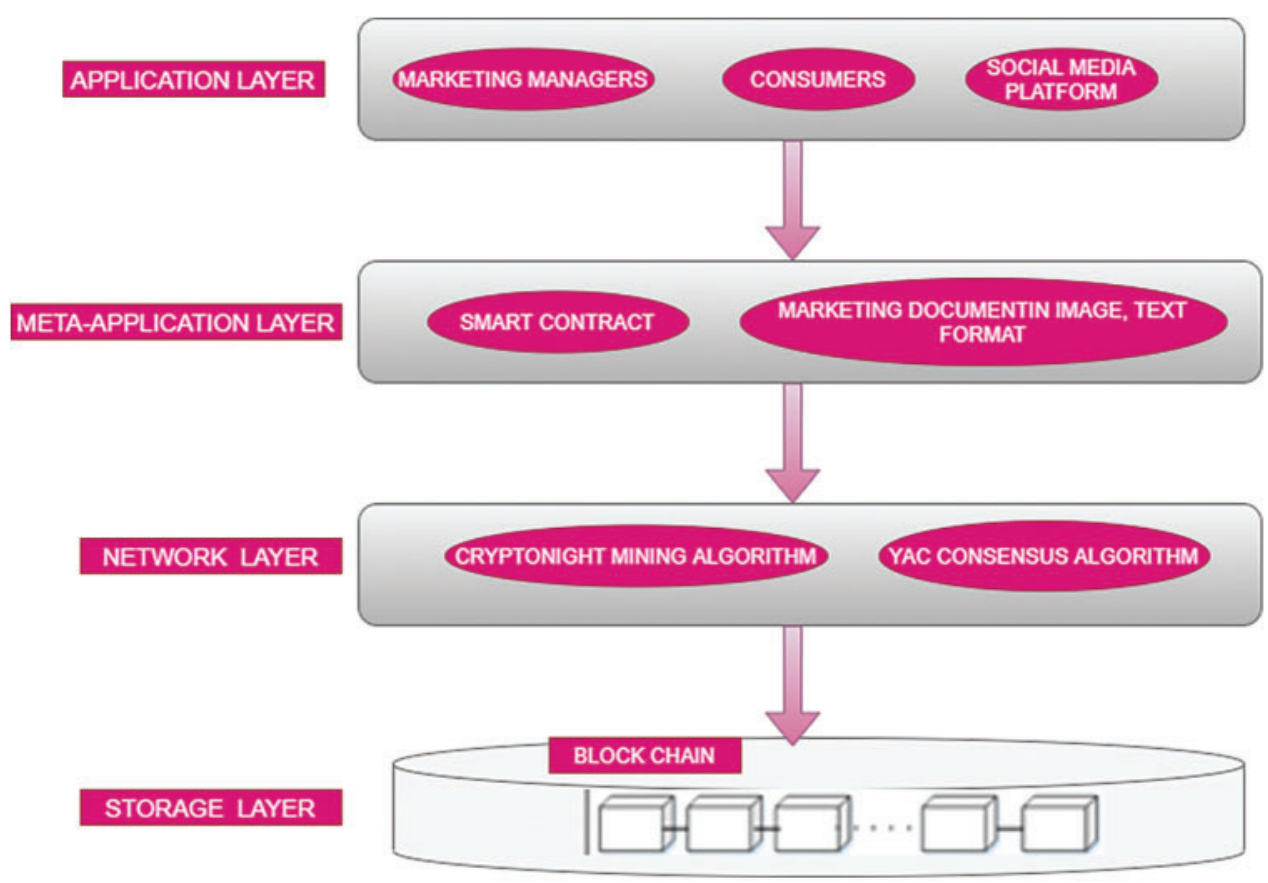

Figure 1: Proposed architecture 
The function of this layers in Blockchain as disruptive technology is collecting transactions from different social media platform, for the secure storage CryptoNight mining algorithm is used, maintaining the data in the ledger by using YAC consensus algorithm for its cryptocurrency and so on.

\subsection{Application Layer}

It is the topmost layer in which marketing managers, consumers can use directly via social media platform and any other authentication platform. Cryptocurrency transaction involved in this layer by exchanging the transaction between several entities.

\subsection{Meta-Application Layer}

This layer is similar to application layer with smart contract. It makes blockchain products more powerful and people can store and share data. Smart contract will automatically execute when conditions are met. That is verifying security process, payment processing and so on.

\subsection{Network Layer (Proposed Work) BCDSMM-CNYAC}

In this layer, blockchain as a disruptive technology data is stored in decentralized form. From that it shared data to the authentic customer in a secure manner through CryptoNight mining algorithm and YAC consensus algorithm. Fig. 2. shows that the impact of blockchain as disruptive technology on social media marketing. Transaction of secure data with a high-speed access, transparency of data and maintain privacy we implement BCDSMM-CNYAC.

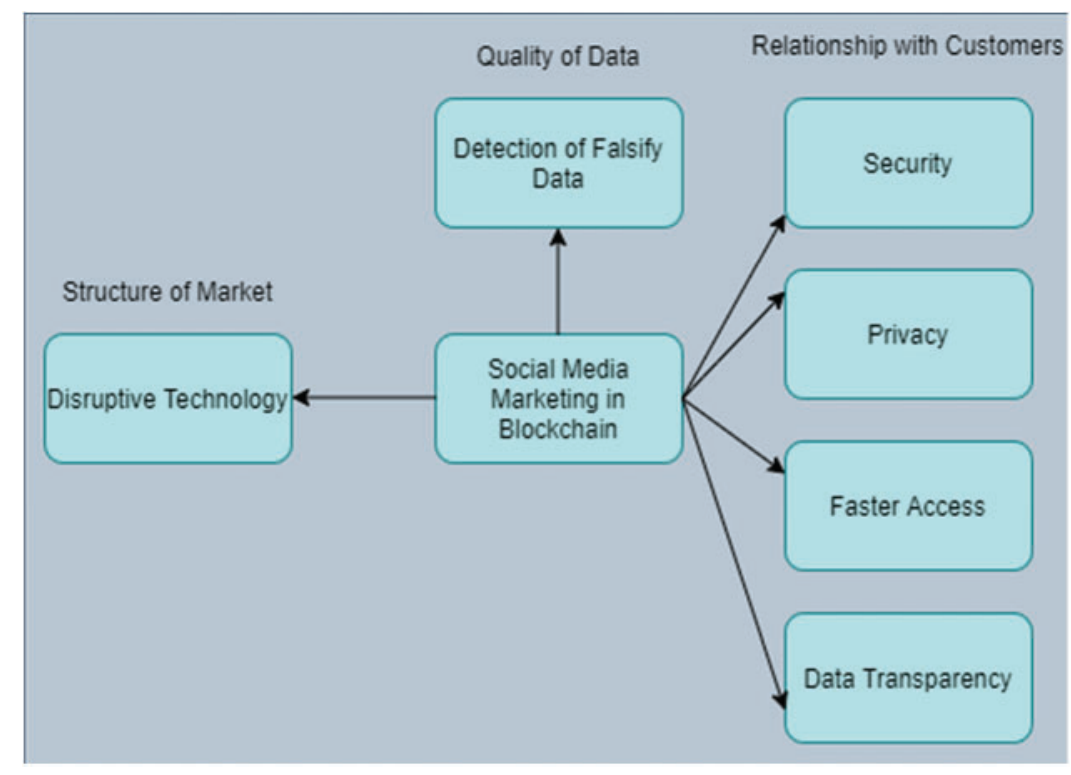

Figure 2: Impact of disruptive blockchain on social media marketing 
The main concepts of Blockchain as disruptive revolution are given below:

Disruptive technology in the social media marketing is transforming the traditional methods into new framework of technology by enhancing the life style quality insatisfying the consumer's needs easier, faster in the field of online product seller or providers. The properties of Blockchain as disruptive technology is given below:

$\checkmark$ Track and data store-The decentralised and distributed system across an extensive network of computers becomes a safe way to track data changes over time.

$\checkmark$ Trust-The system allows us to interact directly with our data in real-time and the network, all the computers verify the changes in the transactions which creates trust in the data.

$\checkmark$ Peer-to-peer transactions-in this system there is no more intermediaries. Sharing of data directly with peers.

Tab. 2. shows the summary of some blockchain technology based social media marketing platforms and traditional social media marketing platform.

Table 2: Summary of TSMM and BSMM

\begin{tabular}{ll}
\hline Traditional social media & Blockchain based social media \\
\hline Facebook & Foresting \\
Twitter & Peepth \\
LinkedIn & Indorse \\
Instagram & Steepshot \\
\hline
\end{tabular}

\subsubsection{Cryptonight Mining Algorithm}

CryptoNight Mining Algorithm is a mining algorithm used for improving CPU efficient and ASIC resistant. Data stored in decentralization mode of the mining of cryptocurrencies that offer advanced privacy and anonymity. CryptoNight uses the mining scheme of Proof of Work (PoW) for its operationand it offer a high dependence on CPU, resisting ASIC.

\section{Preliminaries:}

Hash function: It generate random hash value in a string of bytes with fixed length. This hash value is used to identify the transaction on the blockchain.

Scratchpad: It evaluate a memory-hard function intermediate values and store it in a memory area called scratchpad.

The steps involved in the CryptoNight is given below:

Step 1: Scratchpad initializationwith pseudo-random data.

Step 2: Memory-hard loop function

Step 3: Hashing Value

Scratchpad contains several read/writeoperations are stored at pseudo-random number addresses. The Flow diagram of CryptoNight mining algorithm is given in Fig. 3. 


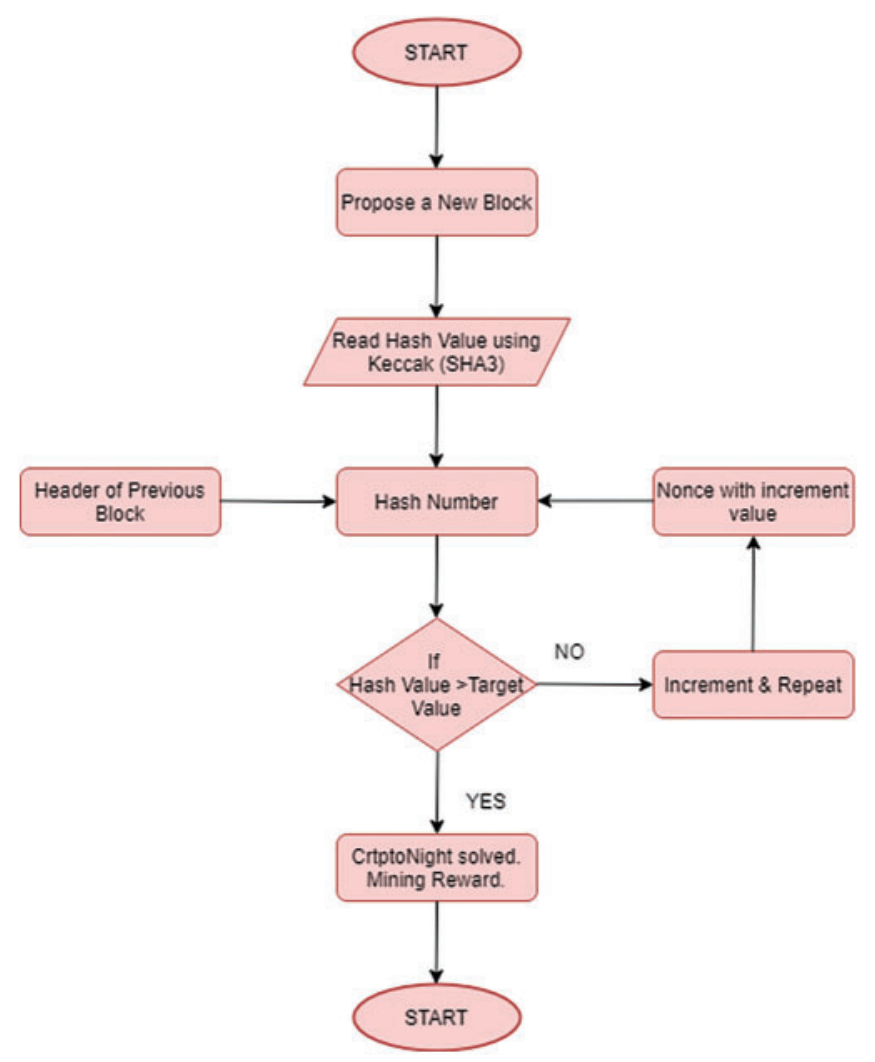

Figure 3: Flow diagram of cryptonight mining algorithm

\subsubsection{YAC Consensus Algorithm}

This consensus algorithm is used for providing more secure and accuracy in social media marketing data.

\section{Preliminaries of YAC consensus algorithm:}

Client: The role of the client is generating the people's request and send them to the ordering service (OS) along with public key.

Peer: Node of the network and responsible for validate and store data into the blocks.

Ordering Service (OS): The ordering service is orders data transactions into a known order.

In YAC consensus algorithm, people/customer is considered as peer and customer can interact with all other known peers via private key. YAC consensus algorithm of blockchain technology can be described by the following steps.

Procedure for YAC consensus algorithm:

Step 1: Customer A creates a data transaction with private key

Step 2: Customer A's transaction is sent to all other known peer. The receiver peer (Customer B) receives the transaction, and verify the transaction is valid or not.

Step 3: An unsigned block is created by OS and shared to peers in the network. The unsigned block is called as proposal. 
Step 4: After verifying the proposal, peers calculate the hash value and sign it called as vote.

Step 5: From the step 4, for each peer in the network, hash value is created and computes the order of peers. The first peer in the ordering list is called leader.

Step 6: Voting peer is created by hash value for the proposed block.

Step 7: All votes are collected from other peers in the network through leader and identify the supermajority of vote. Then commit message is send to committing block.

Step 8: At the receiver peer, this commit message is verified and block is added into the ledger. YAC consensus is completed and verify it as a valid one.

By applying the above procedure, the social media data stored in the blockchain gain more secure, accuracy and consistency. After executing the step 1 to step 9, block is added into the chain by using Algorithm 1.

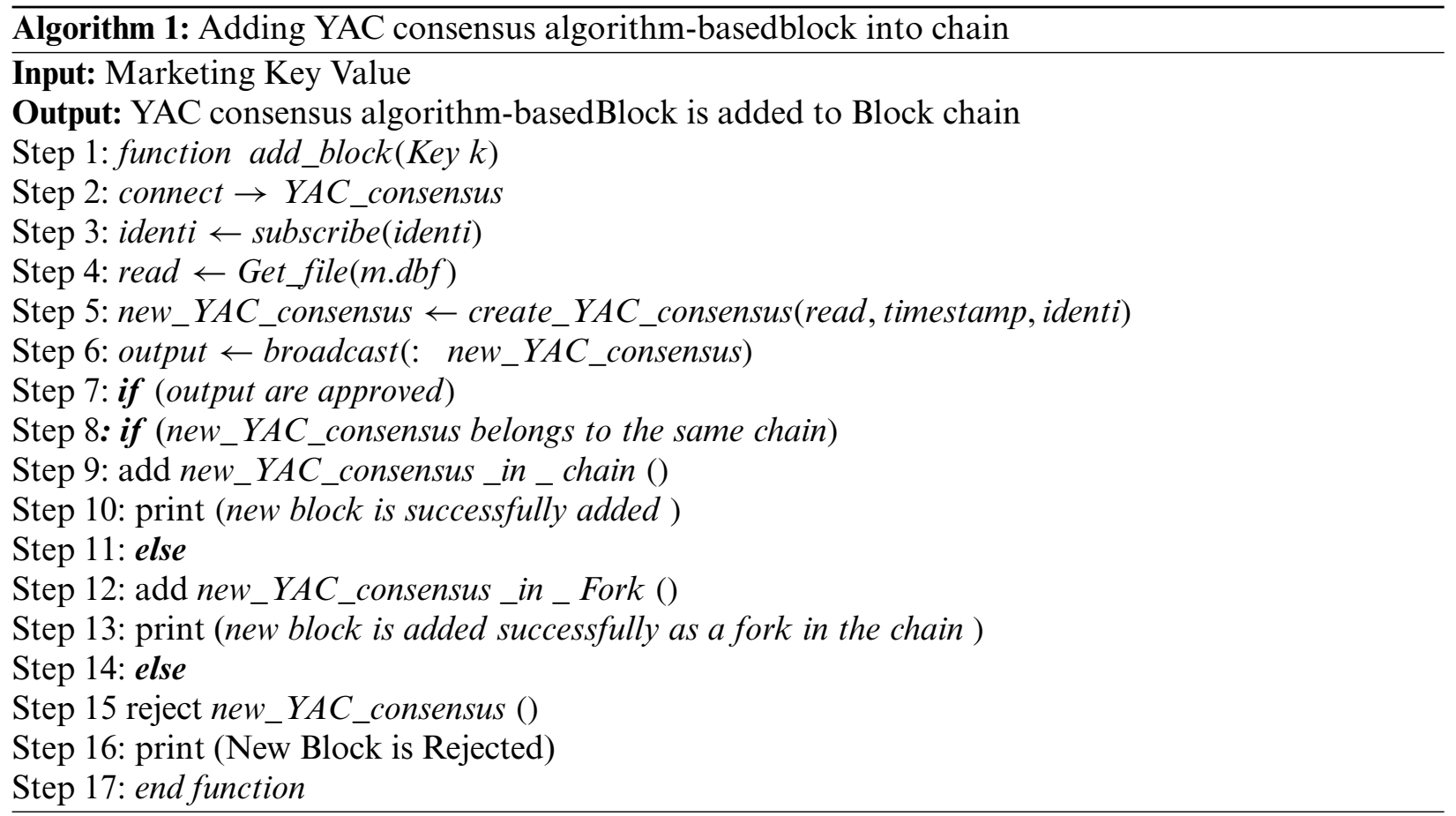

\subsection{Storage Layer}

This is a bottom layer in which data are stored in blocksand create the chain. The stored data in the chain is verified, then permanently stored in the ledger. This ledger is kept as transparency for the public use. Fig. 4 shows how message is stored in social media platform using Blockchain technology. The features of blockchain as disruptive technology in social media platform are given below:

- Data Transparency

- Data authenticity and security: After verification is done, sharing authentic and secure data publicly.

- Permanent storage data: No modification is allowed. 
- Decentralized Ledger: Computes parallel computing.

- Crypto-currency: Provides compensative to the active participants.

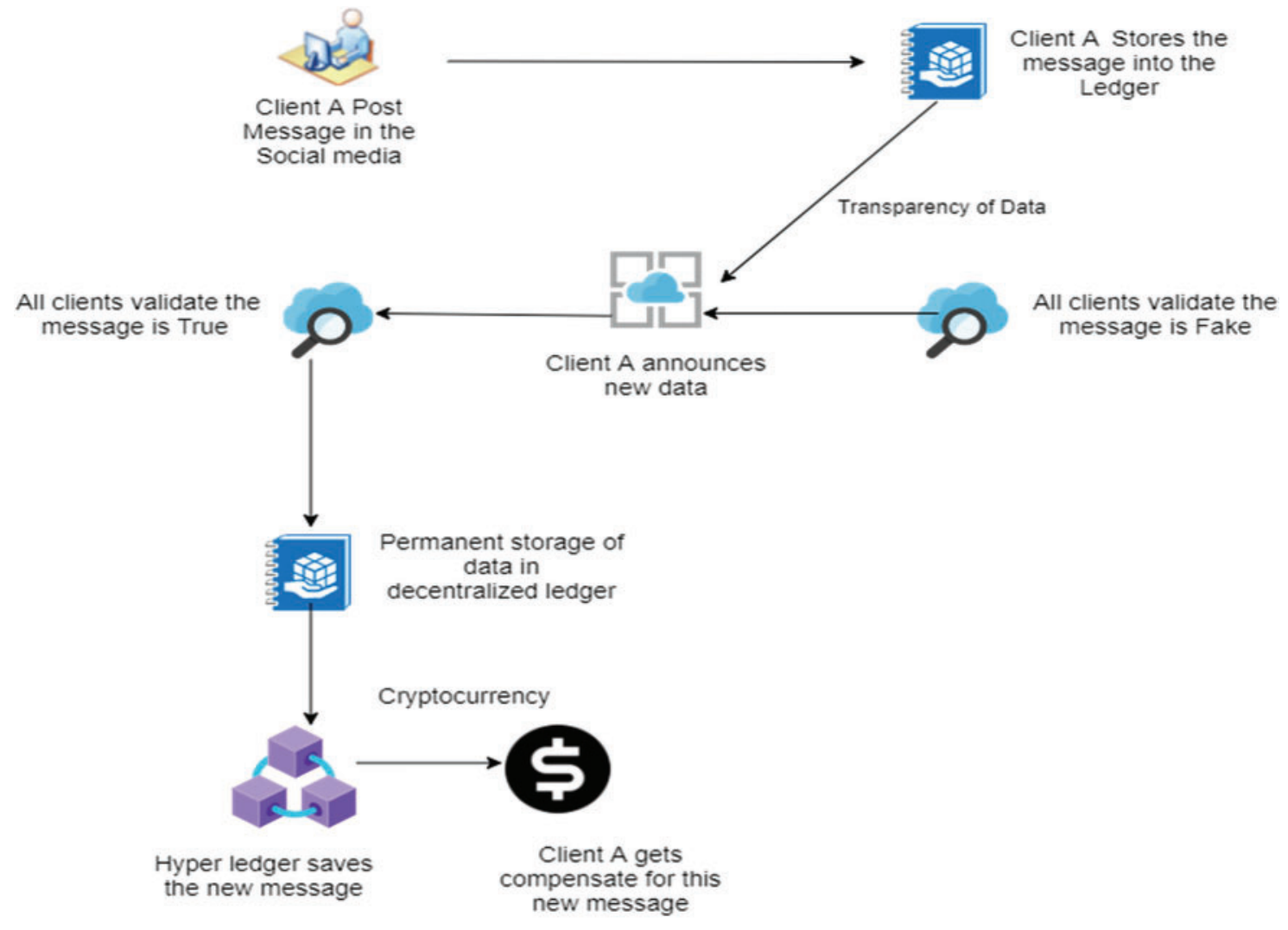

Figure 4: Message stored in social media platform using blockchain technology

\section{Result Analysis}

The analysis of blockchain based disruptive technology in the social media marketing is based on quantitative approach to set a structured type questionary. Taking survey in the online through social websites and collecting the responses for the questionaries. Based on these responses we can take a decision in buying a product in the social media platform. The information in the questionnaire contains demographics and usage of product, indirect questions to make a customer to buy a product and expectation-based questions about the product in the social media marketing. The respondents were registered their opinion with the questionary provided regrading usage of social media marketing. The questions used 5 points of scoring value in the range of 1 indicates "Strongly Disagree", 2 indicates "Disagree", 3 indicates "Neutral", 4 indicates "Agree" and 5 indicates "Strongly Agree".This survey questionnaire was prepared in the Google document format and the link was sent to the users via various social media platforms like Twitter, Facebook, Instagram, LinkedIn etc. The questionnaire respondents of people from various social media platform are posted on their own profile itself. 200 respondents of customers for the questionnaire are collected from social media platform. In this work, social media addiction level of people is evaluated by using multiple regression analysis and one-way 
Analysis of variance (ANOVA) were used in the data analysis. Tab. 3 shows the Demographic detailsof 500 respondent of consumers form their profile.

Table 3: Survey respondent of people on social media platform

\begin{tabular}{lll}
\hline Respondent of people on social media platform & \\
\hline Age & Male & Female \\
\hline$<18$ & 90 & 110 \\
$18-30$ & 110 & 135 \\
$31-50$ & 15 & 30 \\
$51-70$ & 5 & 5 \\
\hline
\end{tabular}

Tab. 4 contains daily time spent on the social media platform. Social media is now become a part of our daily activities. Most of the people spending more than $3 \mathrm{~h}$ in the social media. This is very important for the marketers to explore their product for sale/promote in the social media. Tab. 5 shows the frequency range value of visiting social media platform on the daily basis.

Table 4: Time spent on social media

\begin{tabular}{ll}
\hline Time spent on social media platform & \\
\hline Hours & No. of people \\
\hline None & 25 \\
Less than $1 \mathrm{~h}$ & 80 \\
$1-3 \mathrm{~h}$ & 270 \\
$4-8 \mathrm{~h}$ & 100 \\
$9 \mathrm{~h}$ and more & 25 \\
\hline
\end{tabular}

Table 5: Contains daily frequency of times visiting social media profiles

\begin{tabular}{ll}
\hline \multicolumn{2}{l}{ Number of times visiting social media } \\
\hline Visiting times & No. of people \\
\hline Never & 10 \\
$1-5$ times & 90 \\
$6-20$ times & 280 \\
$21-40$ times & 90 \\
Always & 30 \\
\hline
\end{tabular}

In the Fig. 5. shows the respondent collected from survey $16 \%$ respondents believe in sharing their opinions, experience and views about the product in social media platform. Through social media $42 \%$ respondent are connected with their friends. $5 \%$ of respondents are playing games. 


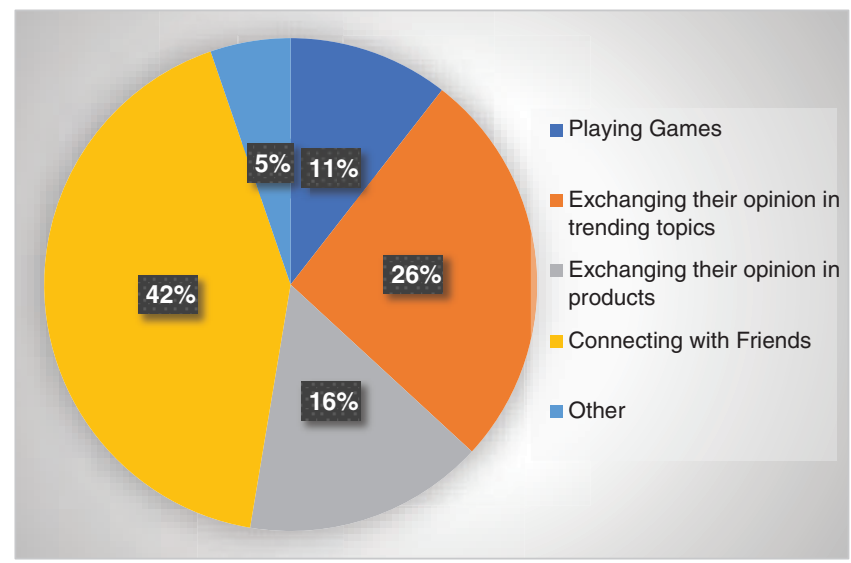

Figure 5: Usage of social media platform

For exchanging their opinions about current trending problem in the society $26 \%$ respondents are used social media platform. $5 \%$ respondents are used social media platform for other activities.

\subsection{Data Analysis}

Multiple regression analysis and one-way Analysis of variance (ANOVA) were used in the data analysis.

$F=\frac{M S T}{M S E}$

$M S T=\frac{S S T}{p-1}$

$M S E=\frac{S S E}{N-p}$

$S S E=\sum(n-1) S^{2}$

$S S T=\sum_{i=1}^{n}\left(x_{i}-\bar{x}\right)^{2}$

$F$ is ANOVA coefficient

$M S T$ is Mean of Sum of Squares

$M S E$ is Mean sum of squares due to error

$S S T$ is Total sum of Squares

$p$ is total number of populations

$n$ is total number of samples in a population.

$N$ is total number of observations

$s$ is Standard deviation of the samples 
Tab. 6 shows the result of ANOVA by using "age" factor in our proposed work (BCDSMMCNYAC).

Table 6: ANOVA result using BCDSMM-CNYAC in "Age" factor

\begin{tabular}{llllll}
\hline Age & N & SST & Mean square & F & $\begin{array}{l}\text { Statistical } \\
\text { significant }\end{array}$ \\
\hline$<18$ & 200 & 3.718 & 3.718 & 2.046 & 1.21 \\
$18-30$ & 245 & 4.341 & 4.341 & 2.167 & 1.32 \\
$31-50$ & 45 & 1.721 & 1.721 & 1.045 & 0.324 \\
$51-70$ & 10 & 0.672 & 0.672 & 0.121 & 0.067 \\
\hline
\end{tabular}

ANOVA test is conducted for the respondents of 500 in the social media users at different age groups. The observed result from Tab. 5. the significant difference in the significant difference in age group increases with age up to 30 and decreases in the age group of 31-50. Tab. 7. shows the result of ANOVA with respect to time spent on social media in the daily basis.

Table 7: ANOVA result using BCDSMM-CNYAC in "time spent" factor

\begin{tabular}{llllll}
\hline Hour & $\mathrm{N}$ & SST & Mean square & $\mathrm{F}$ & $\begin{array}{l}\text { Statistical } \\
\text { significant }\end{array}$ \\
\hline Less than 1 h & 80 & 85.98 & 32.95 & 1.321 & 0.21 \\
$1-3 \mathrm{~h}$ & 270 & 115.67 & 24.75 & 2.167 & 0.43 \\
$4-8 \mathrm{~h}$ & 100 & 97.45 & 18.77 & 1.021 & 0.86 \\
$9 \mathrm{~h}$ and more & 25 & 55.23 & 21.32 & 1.684 & 0.16 \\
\hline
\end{tabular}

The observed result from Tab. 7. time spent in the social media usage level increases vividly in the daily basis. Tab. 8 shows ANOVA result of daily revising times of social media platform.

Table 8: ANOVA result using BCDSMM-CNYAC in "Frequency visit" factor

\begin{tabular}{llllll}
\hline Visiting times & N & SST & Mean square & F & $\begin{array}{l}\text { Statistical } \\
\text { significant }\end{array}$ \\
\hline Never & 10 & 25.31 & 17.55 & 20.12 & 0.12 \\
1-5 times & 90 & 112.98 & 12.75 & 80.34 & 0.78 \\
6-20 times & 280 & 217.31 & 28.77 & 98.56 & 0.92 \\
21-40 times & 90 & 94.72 & 19.45 & 34.78 & 0.56 \\
Always & 30 & 45.89 & 21.48 & 53.26 & 0.67 \\
\hline
\end{tabular}

The observed result from Tab. 8 , indicates that the frequency visit of social media marketing increases. Fig. 6 shows that respondents are using social media to make decision in buying the product. Majority of consumers always use the social media review comments to buy a product in the online. Therefore, most of the marketers put their details of product on the social media platform and receiving consumer's positive note about their product. 


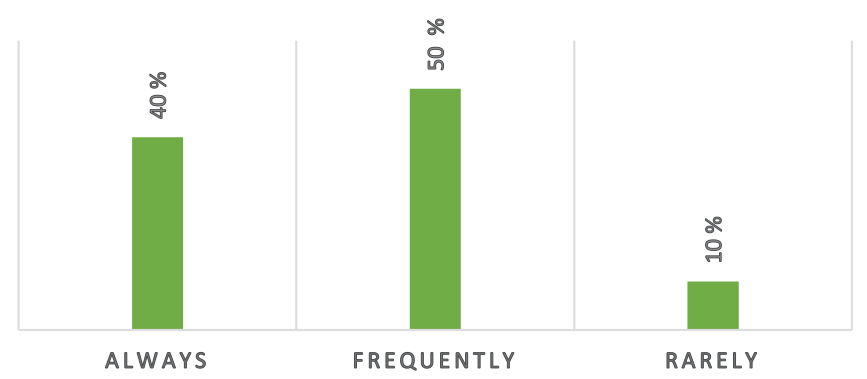

Figure 6: Decision by consumer's in buying product on social media

\subsection{Reliability Analysis} of view.

It is used to measure the reliability of the product regarding to the opinion of the consumers point

For that we are using Cronbach's alpha value.

$\propto_{s t}=\frac{N \cdot \bar{r}}{1+(N-1) \cdot \bar{r}}$

$\mathrm{N}$ is number of questions

$\mathrm{R}$ is correlation between the questions. In this analysis, we consider opinion of 100 consumers about the product. Tab. 9 shows the Cronbach's alpha tests value of consumers openness view about the product.

Table 9: Reliability of product using cronbach's alpha value

\begin{tabular}{ll}
\hline Cronbach's Alpha & $\begin{array}{l}\text { Internal consistency } \\
\text { value }\end{array}$ \\
\hline$\alpha \geq 0.9$ & Excellent \\
$0.9>\alpha \geq 0.8$ & Good \\
$0.8>\alpha \geq 0.7$ & Acceptable \\
$0.7>\alpha \geq 0.6$ & Questionable \\
$0.6>\alpha \geq 0.5$ & Poor \\
$0.5>\alpha$ & Unacceptable \\
\hline
\end{tabular}

This analysis is used to identify impact of consumer's behaviour about the product in the social media marketing. Fig. 7 shows that sample product opinion of consumers using Cronbach's Alpha value.

From the Fig. 7, it is observed that people want to buy a product in the social media platform, social media review has excellent level of reliability with Cronbach's value alpha $\alpha \geq 0.9$. Therefore, consumers are using social media platform to make decision in buying the product. The Brand product has good level of reliability with Cronbach's value alpha $0.9>\alpha \geq 0.8$. The advertising has an acceptable level of reliability with Cronbach's value alpha $0.8>\alpha \geq 0.7$. 


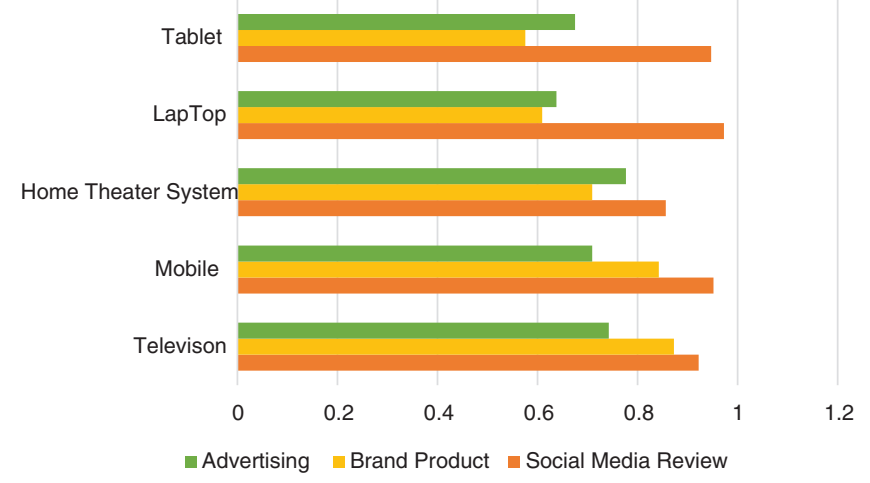

Figure 7: Reliability of product using cronbach's alpha value

\section{Conclusion}

This paper presented blockchain as disruptive technology for social media marketing and provide information in a secure, faster access by using CryptoNight mining algorithm with YAC consensus algorithm. Under this BCDSMM-CNYAC work, it avoids posting of fake information on social media and increase CPU efficiency. From Tabs. 5-7 the usage of social media increases dramatically for all age groups and time spent in the social media also increases. So, the marketers/consumers have adequate space to sell/buy product in the online and communicate with consumers directly or indirectly. It is easy to access and promote their product in faster and secure manner. Consumers prefer social media platform for online marketing. They put reliable on them in developing their social media marketing. Our proposed BCDSMM-CNYAC is a best platform for marketing the product in the social media at reasonable cost. Blockchain technology as disrupt the outperformed in an effective way. But in the future work is based on decentralized system of social media marketing and also empirical analysis is applied in the social media marketing for know about consumer behavior.

Acknowledgement: The authors extend their appreciation to the Deanship of Scientific Research at King Khalid University for funding this work under Grant Number (RGP 2/209/42).

Funding Statement: This research was funded by the Deanship of Scientific Research at Princess Nourah bint Abdulrahman University through the Fast-Track Path of Research Funding Program.

Conflicts of Interest: The authors declare that they have no conflicts of interest to report regarding the present study.

\section{References}

[1] K. Kapanova, B. Guidi, A. Michienzi and K. Koidl, "Evaluating posts on the steemit blockchain: Analysis on topics based on textual cues," in Proc. 6th EAI Int. Conf. on Smart Objects and Technologies for Social Good, Antwerp, Belgium, pp. 163-168, 2020.

[2] Z. Y. Chen, Z. P. Fan and M. Sun, "Individual-level social influence identification in social media: A learning-simulation coordinated method," European Journal of Operational Research, vol. 273, no. 3, pp. 1005-1015, 2019.

[3] B. Batrinca and P. C. Treleaven, "Social media analytics: A survey of techniques, tools and platforms," AI \& Society, vol. 30, no. 1, pp. 89-116, 2015.

[4] G. Rathnakar, "Blockchain marketing through social media surges the economic growth of India," International Journal of Recent Technology and Engineering, vol. 8, no. 1, pp. 78-81, 2019. 
[5] T. M. Choi, "Blockchain-technology-supported platforms for diamond authentication and certification in luxury supply chains," Transportation Research Part E: Logistics and Transportation Review, vol. 128, pp. 17-29, 2019.

[6] T. M. Choi, S. Guo and S. Luo, "When blockchain meets social-media: Will the result benefit social media analytics for supply chain operations management?," Transportation Research Part E: Logistics and Transportation Review, vol. 135, pp. 101860, 2020.

[7] M. Hamilton, V. D. Kaltcheva and A. J. Rohm, "Social media and value creation: The role of interaction satisfaction and interaction immersion," Journal of Interactive Marketing, vol. 36, pp. 121-133, 2016.

[8] J. Järvinen, A. Tollinen, H. Karjaluoto and C. Jayawardhena, "Digital and social media marketing usage in B2B industrial section," Marketing Management Journal, vol. 22, no. 2, pp. 202-210, 2012.

[9] M. Faßmann and C. Moss, "Charakterisierung and positionierung der social-media-plattformen," in Instagram als Marketing-Kanal, Wiesbaden: Springer VS, pp. 23-33, 2016.

[10] D. Susilo, N. Christantyawati, I. J. Prasetyo and S. R. Juraman, "Content analysis of LINE application user: Intersecting technology and social needed," Journal of Physics: Conference Series, IOP Publishing, vol. 1175, no. 1, pp. 1-7, 2019.

[11] F. Li, J. Larimo and L. C. Leonidou, "Social media marketing strategy: Definition, conceptualization, taxonomy, validation and future agenda," Journal of the Academy of Marketing Science, vol. 49, no. 1, pp. 51-70, 2021.

[12] I. Maiorescu, M. Bucur, B. Georgescu, D. Moise, V. A. Strat et al., "Social media and IOT wearables in developing marketing strategies. Do SMEs differ from large enterprises?," Sustainability, vol. 12, no. 18, pp. 7292, 2020.

[13] P. Grover, A. K. Kar and M. Janssen, "Diffusion of blockchain technology: Insights from academic literature and social media analytics," Journal of Enterprise Information Management, vol. 32, no. 5, pp. 735-757, 2019.

[14] K. Seong Kyu and J. Huh, "Blockchain of carbon trading for UN sustainable development goals," Sustainability, vol. 12, no. 10, pp. 4021, 2020.

[15] S. Fosso Wamba, J. R. Kala Kamdjoug, R. Epie Bawack and J. G. Keogh, "Bitcoin, blockchain and fintech: A systematic review and case studies in the supply chain," Production Planning \& Control, vol. 31, no. 2, pp. 115-142, 2020.

[16] A. Rejeb, J. G. Keogh and H. Treiblmaier, "How blockchain technology can benefit marketing: Six pending research areas," Frontiers in Blockchain, vol. 3, pp. 1-12, 2020.

[17] A. Rejeb, J. G. Keogh and H. Treiblmaier, "Leveraging the internet of things and blockchain technology in supply chain management," Future Internet, vol. 11, no. 7, pp. 1-14, 2019.

[18] A. Ghose, P. G. Ipeirotis and B. Li, "Modeling consumer footprints on search engines: An interplay with social media," Management Science, vol. 65, no. 3, pp. 1363-1385, 2019.

[19] J. Ma, Y. K. Tse, X. Wang and M. Zhang, "Examining customer perception and behaviour through social media research-An empirical study of the united airlines overbooking crisis," Transportation Research Part E: Logistics and Transportation Review, vol. 127, pp. 192-205, 2019.

[20] A. Ghose, "What blockchain could mean for marketing," Harvard Business Review, vol. 5, pp. 2-5, 2018.

[21] P. Pekgün, M. R. Galbreth and B. P. Ghosh, "How unequal perceptions of user reviews impact price competition," Decision Sciences, vol. 49, no. 2, pp. 250-274, 2018.

[22] D. Lee, K. Hosanagar and H. S. Nair, "Advertising content and consumer engagement on social media: Evidence from facebook," Management Science, vol. 64, no. 11, pp. 5105-5131, 2018.

[23] R. Hou, R. Koster and Y. Yu, "Service investment for online retailers with social media-Does it pay off?," Transportation Research Part E: Logistics and Transportation Review, vol. 118, pp. 606-628, 2018.

[24] A. Singh, N. Shukla and N. Mishra, "Social media data analytics to improve supply chain management in food industries," Transportation Research Part E: Logistics and Transportation Review, vol. 114, pp. 398415, 2018.

[25] D. Gunnec and S. Raghavan, "Integrating social network effects in the share of choice problem," Decision Sciences, vol. 48, no. 6, pp. 1098-1131, 2017. 
[26] U. Ramanathan, N. Subramanian and G. Parrott, "Role of social media in retail network operations and marketing to enhance customer satisfaction," International Journal of Operations \& Production Management, vol. 37, no. 1, pp. 105-123, 2017.

[27] I. Lobel, E. Sadler and L. R. Varshney, "Customer referral incentives and social media," Management Science, vol. 63, no. 10, pp. 3514-3529, 2017.

[28] J. F. Hair, R. E. Anderson, B. J. Babin and W. C. Black, "Multivariate Data Analysis: A global perspective" ISO 690, vol. 7ed: Upper Saddle River, NJ: Pearson, 2010. 